\title{
A Study of Principle of Conversation in Advertising Language*
}

\author{
Fang Liu \\ Changchun University of Science and Technology, Changchun, China \\ Email: 2005xiaoji@163.com
}

\begin{abstract}
Principle of Conversation includes Grice's Cooperative Principle (CP) and Leech's Politeness Principle (PP). Advertising language can produce conversational implicatures and exert stronger persuasive effect by observing and violating the Cooperative Principle. At the same time, some public service advertisements comply with the Politeness Principle. The paper offers a wider way for advertising designers to create excellent advertisements and also make them pay attention to some problems existing in ads. On the other hand, it is also of great help for consumers to understand the implied meaning of advertisements and avoid being tempted into buying some poor quality products by some deceptive advertising.
\end{abstract}

Index Terms - the Cooperative Principle, the Politeness Principle, advertising language, conversational implicature, influencing factors

\section{INTRODUCTION}

In modern society, advertising has invaded every aspect of our life. It has exerted great impact on modern people's lifestyles. We are surrounded by various kinds of advertisements. Whenever we open a newspaper or a magazine, turn on the TV or the radio, or look at the billboards in subways or on buildings, we are exposed to various advertisements. Since advertisements have penetrated our lives deeply, studies on it have been carried on before and more attention on it also appears necessary. As a special form of communication, most commercial advertisements are actually a kind of persuasive speech act with an aim to persuade consumers into buying or accepting certain product or service. To achieve this purpose, advertisers frequently employ strategies and skills in advertising language. Researches show that people pay attention to what interests them and ignore what doesn't. In order to arouse people's attention, advertisements express the ideas indirectly by applying Principle of Conversation, which leads to conversational implicature.

Principle of Conversation includes Grice's Cooperative Principle (CP) and Leech's Politeness Principle (PP). A philosopher and logician, Paul Grice made an attempt to explain the course of natural conversation, in which implied messages are frequently involved. His idea is that in making conversation, the participants must first of all be willing to cooperate; otherwise, it would not be possible for them to carry on the talk. This general principle is called the Cooperative Principle, abbreviated as CP. There are four maxims under this general principle: the maxim of quantity, the maxim of quality, the maxim of relation and the maxim of manner (Dai\&He, 2010). Based on the Cooperative Principle, the paper analyzes advertisements. Advertising language can produce conversational implicatures by violating the maxims of the Cooperative Principle. Herbert Paul Grice (1967) originally suggested the theory of conversational implicature. The term "implicature" is used by Grice to account for what a speaker can imply, suggest, or mean, as distinguished from what the speaker literally says. A conversational implicature is something which is implied in conversation, that is, something which is left implicit in actual language usage. Grice coined the term implicature. And he explored the question how people manage to convey implicature, which is not explicitly expressed (Hu, 2006, P.191). In certain cases, we are dealing with conversational implicature. Somebody may think the advertisers follow the maxims of the Cooperative Principle. But the fact is not like that, for they make ads just in the opposite way. People can find that the ads in any newspaper or magazine, a poster or a billboard anywhere in town flout at least one maxim. By doing so, advertisers can compete for consumers' attention.

Apart from the Cooperative Principle, which is taken as the general guidelines to successful human communication, there are other principles guiding speech acts, of which the Politeness Principle (PP) draws most attention from people (Chen, 2006). G. Leech (1983) has made great contributions to the further study of the Politeness Principle (PP), including Tact Maxim, Generosity Maxim, Approbation Maxim, Modesty Maxim, Agreement Maxim and Sympathy Maxim. Some advertisements, such as the public service advertisements usually observe the Tact Maxim, Generosity Maxim and Sympathy Maxim of Leech's Politeness Principle. Public service advertising is the use of commercial advertising techniques for non-commercial purposes. The consciousness of the masses can be called together through the public service advertising.

\footnotetext{
* Note: This paper is sponsored by JLPOPSS with the code of 2010B29.
} 


\section{The OBSERVATION OF THE CP IN AdVERTISING LANGUAGE}

When the addresser is observing the maxims in a direct way, he may expect the addressee to make his inferences on the assumption that the addresser is following the maxims of conversation. This means both the addresser and the addressee assume that they are following the conversational maxims. The addressee interprets the addresser's statement and makes inferences in order to preserve the assumption of cooperation. As for advertising, it's the advertiser addressing to the consumers. For their own purposes, they will take advantage of the implicatures generated by observing the maxims of the CP. For example:

(1)My Goodness! My Guinness!

---Guinness Beer

Obviously, the meaning of this advertisement is not given directly. However, in order to infer the implied meaning of this ad, the reader must assume that the advertiser is observing the conversational maxims. Thus, the reader can get the implied meaning by thinking about the relation between "My Goodness" and "My Guinness". According to the maxim of Relation, whenever something is said, there must have been some related reason; otherwise the utterance will not make any sense. "My Goodness!" is an exclamatory sentence which is used to express something amazing or something that is out of one's expectation. Thus the implied meaning of this ad must be that drinking Guinness beer can make people feel good and have very strong feeling to say "my goodness". This example shows us that the maxims of Relation as a principle of communication can be the trigger of further conclusions. The implicature in the exemplified ad certainly works better than telling readers directly that the Guinness beer is good. By employing the strategy of implicature, the advertisers deliberately cause their readers extra processing effort. Since advertisers' initial goal is to draw consumers' attention and create their interest, extra processing effort may add extra attention-holding effect. Moreover, inferring an indirect meaning on the basis of maxims of Relation can give rise to a pleasant feeling, springing from a sort of intellectual satisfaction. Increased memorability is thus a major advantage derived from conversational implicatures in advertising.

Besides the maxim of Relation, conversational implicatures in advertising are sometimes also based on the observation of the maxims of Quantity, Quality and Manner.

(2)One thing that definitely isn't changing is our world-class service and support.

---Digital Computer Company

(3)The Altima is built with such precision that it had an average gap difference of just 0.18 inches.

---Altima Car

(4)And the holiday starts as soon as you board Air New Zealand, with friendly staff on each of the 32 flights from Asia \& Japan every week.

--- New Zealand Air Line

In the above three ads, the advertisers claim the specific point of their advertised products or services. According to the maxims of Quantity- "Make your contribution as informative as is required for the current purposes of the exchange" (Dai\&He, 2010, P.92), in the first ad, the advertiser indicates that their world-class service and support is always as good as that in the past. That is the only thing that is not changed. Consumers can be confident of them. While in the second and the third ad, the advertisers observe the maxims of Quantity and make the ads more clearly and definitely by using the specific numbers " 0.18 ", "each of the 32 flights...every week", which make the advertisements more credible.

\section{The Violation OF The CP IN AdVERTising LANGUAGE}

People communicate with each other on the basis of conforming to the CP maxims on some level. But if the advertisers fail to observe the maxims, they must do so with the intention of attracting more consumers to pay attention to their products or services. And flouting occurs when the advertisers obviously fail to observe the maxims, which leads to the production of implicature. The following is going to show some examples to see how maxims are flouted.

\section{A. The Violation of the Quantity Maxim}

According to Grice, when a speaker blatantly gives more or less information than the situation requires, flouting of the maxims of Quantity occurs. In advertising, if the advertiser leaves out some information, he must be doing it purposely. And since the brief and short ads can make people memorize easily and achieve the promotion effects, most of the slogans or headlines are succinct. Obviously this flouts the maxims of Quantity that needs to make required information. The following are ads made by NOKIA Mobile

(1) Connecting people.

---NOKIA Mobile

As for this ad, people may ask "Who or what connects people?", for the important information is absent in the ad. But if the audiences know it's about NOKIA mobile, they can get the implicature by themselves and know it implies that NOKIA mobile phones connect people. Especially when people open the NOKIA mobile phone, the picture of grasped hands appear on the screen with the word "connecting people", they can easily infer what the ad implies. It means NOKIA mobile phones can help people communicate well. In this ad, only two words are used but the motive of the advertiser is fully expressed, which directly test the point that providing less information may attract more readers to 
pay attention to the advertised products, though it flouts the maxims of Quantity.

(2) Coke adds life...

---Coca-Cola

According to the maxims of Quantity, the slogan certainly saves a lot specific words that can show the real qualities of Coca-Cola. It flouts the maxims of Quantity. From the ad, people can't get enough information as required. However, by doing so, consumers can easily memorize it and at the same time, their curiosity can be roused. They may wonder what Coke adds to our life? They may even go to find the answers by trying Coca-Cola, which may help to promote Coke. And the thinking process can also impress consumers which will be helpful in establishing brand loyalty.

\section{B. The Violation of the Quality Maxim}

According to Grice (1967), there are several rhetoric devices which typically give rise to the flouting of the maxim of Quality, including pun, metaphor, personification, hyperbole and irony. This kind of flouting is also commonly seen in print ads.

(1) Money doesn't grow on trees. But it blossoms at our branches.

---Lloyd Bank

In this advertisement, the word "branch" also has two meanings. The first one is the literal meaning "branches of the trees"; the second "branch" refers to each branches of the bank. The implicature they really want to convey is that once the customers deposit their money in the Lloyd Bank, their money will increase unceasingly. Pun in this ad gives rise to the flouting of the maxim of Quality

Another example, in the ad for Macintosh computer, the advertisers grasp what the users need and interest. They explain the web functions of the Macintosh computer in eye-catching headline with succinct language. And in the later part of the advertisement, by using irony the advertiser stress the characteristics of the product, that is:

(2) In spite of all this, we're inclined to admit that there's just one thing in the office that won't be made any easier by installing a Macintosh. You might find yourself lining up to use it.

---Macintosh Computer

After stating the advantages of the computer, the advertiser uses "in spite of this" to describe the only disadvantages of installing this kind of computer, that is, people need to line up for using it. The implicature here is this kind of computer is so convenient that people all want to use it.

\section{The Violation of the Manner Maxim}

In advertising, the flouting of the maxims of Manner, especially the sub-maxim "Be brief" and "Avoid ambiguity" is worth more attention. The following ad is the violation of the Manner Maxim:

(1) A better stretch for the long stretch.

---An Airline Agency

In this ad, the first "stretch" means "becoming longer, wider, etc". The second "stretch" refers to "continuous or unbroken period of time". The implicature of the ad is that the airline agency can provide enough space for customers to stretch freely during the long-time travel. The two "stretch"s make customers feel comfortable.

(2) You will go nuts for the nuts you get in Nux.

$---N u x$

"Nux" is the brand name, whose pronunciation is similar to "nuts". While the phrase "go nuts" means being crazy or very enthusiastic about something, and "nuts" here is an adjective. The second "nuts" means fruit consisting of a hard shell with a kernel inside it that can be eaten. These three words being put together not only produce rhyme, but also give the implicature that Nux nuts are so tasty that buyers will go crazy about them.

\section{The Violation of the Relation Maxim}

The demand for Relation simply means that the advertiser should only include information in his message that is relevant. As the life tempo is speeding up, people are increasingly concerned with their own things. To attract their attention and interests and at the same time make them not feel bored is becoming more difficult. Successful ads always closely relate to people's needs and interests. For example:

(1) The only sound you'll hear is praise.

---Lexus Car

(2) Less bread. No jam.

---London Underground

In the two ads, both of them flout the maxims of Relation. In the first ad, from the literal meaning, the "praise" has no relation with the sound of Lexus cars. By flouting the maxims of Relation, the implicature is produced which means that Lexus cars drives smoothly with light sound. And because of the good quality, what you can hear is only people's praise about it and worrying about noises is unnecessary. For the second ad, it is also difficult for us to infer the real meaning that the advertiser wants to convey. Such words like "bread" and "jam" have no relations to the underground. But after weighing the words, you may find the word "jam" also has the meaning of "traffic jam". Consequently the implicature can be easily inferred, which means that "Traveling by London metro, you will spend less money and can avoid traffic jams". 
(3) Our big bird can be fed even at night.

---Air France

Without any information, the readers may wonder what this ad is designed for. The conventional meaning of this may have to do with the bird that is fed by the advertiser, although it makes nonsense. It seems that the advertiser is uncooperative and violates the maxims of Relation since the message is far from connecting Air France. But in fact, this is the kind of metaphor as rhetoric device people encounter in everyday life and consumers can interpret it. The meaning in this ad is that Air France is like a big bird which can fly well, fly anywhere and at any time. This implicature bears the advertising point which can not be more relevant to consumers' needs, especially for those who always travel by plane but are worried about the safety as well as the time schedule problem.

\section{The Application of the PP to Public SERVICE AdVERTising}

The Politeness Principle is generally followed in advertisement. The six maxims of PP in the ad are reflected: First, highlight the interests of customers, stress self-damaged. Second, praise the customers' choice on the face, secretly praise the production. Third, emphasize the same position with customers. Fourth, try to obtain the same feelings with customers. Detailed analysis as followings: most commercial ads will highlight the benefits of the consumers, that is, through the purchase of the product, the consumers will get the benefits. This is also the important point that an ad expresses its communicative intent. At the same time, advertisement will tell the audience that the advertisers pay the cost and efforts, stress that he suffers damage. If the price of the commodity is low, the advertising will emphasize the consumers can get more benefits (such as discounted commodity's ads, daily necessities' ads, etc.); if the price of the commodity is very high, the advertising will avoid the high price and focus on the good quality of the commodity.

The Tact Maxim and Sympathy Maxim of the Politeness Principle are often observed in advertising. Especially in the public service advertising language. Typical topics for public service advertising include public health and public safety issues, emergency preparedness instructions, natural resources conservation information, and other topics of broad interest. Such advertising is generally produced and distributed on a cooperative basis by governmental agencies or nonprofit organizations acting in concert with private advertising and mass media companies.

\section{A. The Observation of the Tact Maxim}

The Tact maxim of PP is specified as minimize benefit to self and maximize benefit to other (Chen, 2006).The Tact maxim, therefore, is the basis of the Politeness Principle and most widely used in the public service advertising. Take the following advertisement for example.

(1) Leave the dirty things to me, keep yourself clean.

Maybe everyone have seen this ad on TV, a dustbin stand on the sidewalk and smile to a young man, at first he feels funny and strange. But when the dustbin says "Leave the dirty things to me, keep yourself clean", the man looks at the wrapper in his hand and put it into the dustbin. On the surface, what the dustbin said have minimized the benefit to itself and maximized the benefit to the young man, it accords to the Tact maxim of PP. Through the use of the Tact maxim, this public service advertising can raise people's environmental-awareness.

(2) A discarded can is kicked from one to another in the subway compartment. A few minutes later, a man picks it up and throws it into the litter bin. Then the narrator says like this "Scored a goal! The competition of the social morality has already started".

The man picking up the discarded can sets an example for the public without considering himself. Obviously, the idea and language of the ad comply with the Tact maxim. This kind of advertisements may achieve the effect that everyone wants to win in the competition of the social morality. We can contribute our share to the harmonious society.

\section{B. The Observation of the Generosity Maxim}

In the public service advertising, the use of the Generosity maxim is also very widely. The Generosity maxim is defined as minimize cost to other and maximize cost to self (Chen, 2006). To the decent and sincere extent, that is, send a message through advertising. Obvious advantages of such ads are usually effective.

(1) A bus is coming. Two little boys rush into it in order to occupy one seat. The rest passengers on the bus look at them. The two boys turned back at the same time and said to an elder woman together "Granny, come and sit here".

At the beginning, you may think the two boys fight the seat for themselves, but in fact both of them want to keep the only seat for the aged woman. The little boys are willing to "self-sacrifice" in order to minimize the cost to other people. So this advertising has observed the Generosity maxim and the intention of it is to invoke the young people to take care of the elderly in the public.

\section{The Observation of the Sympathy Maxim}

The sympathy maxim is defined as minimize antipathy between self and other; maximize sympathy between self and other (Chen, 2006). This includes a small group of speech acts such as congratulation, commiseration, and expressing condolences, all of which is in accordance with Leech's Politeness Principle.

(1) No trading, no killing. 
Some superstars, such as Yao Ming, have shot advertisements about the protection of the endangered wild animals. The public service advertising can touch the heart of every audience. Nowadays, some merchants kill wild animals in order to sell the valuable part of them. Our government takes some measures to deal with the situation. "No trading, no killing"- the slogan shows sympathy for the endangered animals. The government hopes that this advertising can wake up people's consciousness. Everyone should take immediate actions to prevent illegal trading and killing.

Public Service Advertising is used to spread information to the public. In most cases, the advertisements observe the Politeness Principle out of politeness, even at the cost of violating the maxims of the CP. It can achieve special convincing effects on the consumers.

\section{CONCLuSION}

Advertising is a propagating activity that introduces new commodity or services to the public. It aims to arouse the consumers' purchasing interests. Advertising language, as a special form of communication, exerts great and constant influence on the consumers' purchasing action.

The paper analyzes the advertisements based on the Cooperative Principle by Grice and the Politeness Principle by Leech. The addresser may expect the addressee to make his inferences on the assumption that the addresser is following the maxims of conversation. This means both the addresser and the addressee assume that they are following the conversational maxims. The addressee interprets the addresser's statement and makes inferences in order to preserve the assumption of cooperation. As for advertising, it's the advertiser addressing to the consumers. For their own purposes, they will take advantage of the implicatures generated by observing the maxims of the CP. The conversational implicature is generated by the observation of the CP and by the violation of the CP. Conversational implicature or the implied meaning often occurs in advertising language. A lot of examples related to the violation of the maxims of the $\mathrm{CP}$ and the observation of the PP are presented in the paper. The advertising can achieve special effects by applying the principle of conversation. According to Grice, conversational implicatures will occur through flouting the maxims of CP. Implicatures are more persuasive than plain expressions, especially in advertisements. In the communication of advertisements, advertisers often impart information in an indirect way by openly and intentionally flouting the maxims of the $\mathrm{CP}$ in order to allow readers of advertisements to infer the conversational implicature from the literal meaning.

The advertising language also observes Leech's Politeness Principle, particularly the public service advertising. Public service advertising is the use of commercial advertising techniques for non-commercial purposes and the consciousness of the masses can be called together through it. The PP is taken as the general guidelines to successful human communication and it is one of the most effective strategies for planning the language of advertising. The Tact maxim, Generosity maxim and Sympathy maxim of the PP are often applied to advertisements. By using these maxims, the advertisements can gain more attraction and fulfill the ultimate objective of persuading consumers successfully. Public Service Advertising can achieve special convincing effects on the consumers.

\section{REFERENCES}

[1] Brown,G ( 1994). Language and Understanding. Oxford: Oxford University Press.

[2] Brown, P. \& Levinson, S. (1978).Universals in Language Usage: Politeness Phenomena. Cambridge: Cambridge University Press.

[3] Chen Linhua. (2006). An Introduction to Linguistics. Changchun: Jilin University Press.

[4] Dai Weidong \& He Zhaoxiong. (2010). A New Concise Course in Linguistics for Students of English (2nd edn.). Shanghai: Shanghai Foreign Language Education Press.

[5] Fraser, Roger. (1974). Perspectives on Politeness. Journal of Pragmatics, 14: 219-236.

[6] George Yule. (1996). Pragmatics. London: Oxford University Press.

[7] Hu Zhuanglin. (2006). Linguistics: A Course Book (3rd edn.). Beijing: Beijing University Press.

[8] Leech, G. N. (1986). English in Advertising: A Linguistic Study of Advertising in Great Britain. London: Routledge.

Fang Liu was born in Jilin Province, China on October 23rd, 1976, who has obtained Master's Degree of Arts in foreign linguistics and applied linguistics from Jilin University, Changchun, Jilin Province, China, in 2006.

As a LECTURER, she teaches Applied Linguistics at School of Foreign Languages, Changchun University of Science and Technology. One book (as an editor) and two published articles are as follows: [1] The Breakthrough of Three English Skills. (Changchun, Jilin Province: Jilin University Press, 2009); [2] Social Constructivism and Foreign Language Teaching (Changchun, Jilin Province: Chinese Campus Literature, 2009); [3] Task-based Language Teaching Method and College Foreign Language Teaching (Changchun, Jilin Province: 21 Century Foreign Language Teaching and Research, 2008). Her previous research interests are Applied Linguistics and Intercultural Communication. At present she focuses on Intercultural Pragmatics \& Cognitive Linguistics. 